\title{
Lost in Translation: Social Choice Theory is Misapplied Against Legislative Intent
}

\author{
ARTHUR LUPIA* \\ MATHEW D. MCCUBBINS**
}

TABLE OF CONTENTS

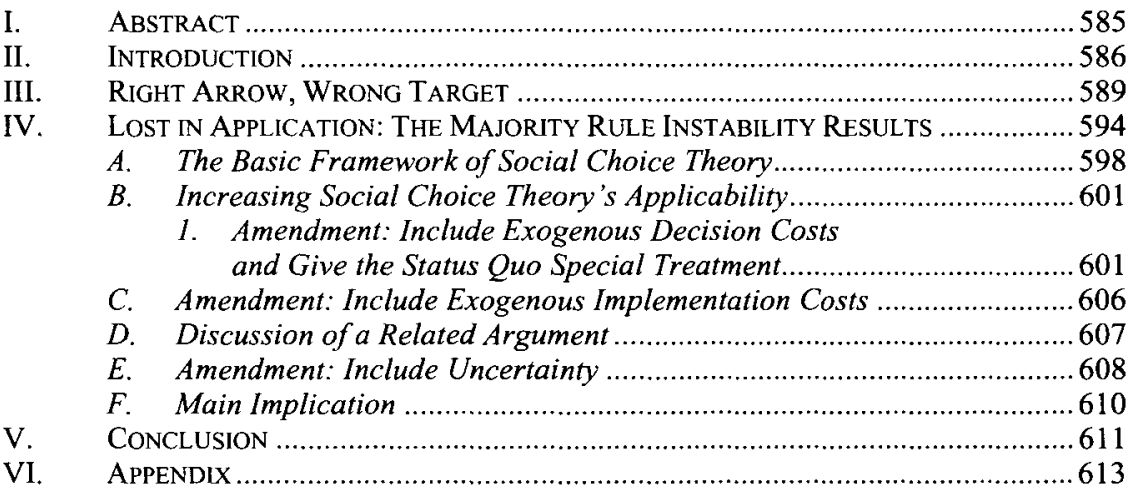

\section{ABSTRACT}

Several prominent scholars use results from social choice theory to conclude that legislative intent is meaningless. We disagree. We support

* Professor of Political Science, University of Michigan.

** Distinguished Professor and Chancellor's Associates Chair, University of California, San Diego. Prepared for a symposium at the University of San Diego School of Law and the UCSD Department of Political Science. We thank Scott Basinger, Jenna Bednar, Adriana Bejan, Cheryl Boudreau, Andrea Campbell, Gary Cox, Chris Den Hartog, James Druckman, Elisabeth Gerber, Bernard Grofman, Adam Levine, Jesse Menning, Nathan Monroe, Norman Schofield, Thomas Schwartz, Kenneth Shepsle, Gisela Sin, Tracy Strong, and Michael Thies for helpful comments. 
our argument by showing that the conclusions in question are based on misapplications of the theory. Some of the conclusions in question are based on Arrow's famous General Possibility Theorem. We identify a substantial chasm between what Arrow proves and what others claim in his name. Other conclusions come from a failure to realize that applying social choice theory to questions of legislative intent entails accepting assumptions such as "legislators are omniscient" and "legislators have infinite resources for changing law and policy." We demonstrate that adding more realistic assumptions to models of social choice theory yields very different theoretical results-including ones that allow for meaningful inferences about legislative intent. In all of the cases we describe, important aspects of social choice theory were lost in the translation from abstract formalisms to real political and legal domains. When properly understood, social choice theory is insufficient to negate legislative intent.

\section{INTRODUCTION}

Is it impossible for a court to discern a legislature's intent when it attempts to interpret vague or ambiguous statutes? The answer to this question is the topic of an important and long-standing debate in legal scholarship. ${ }^{1}$ Some participants in this debate advise courts to seek out the legislative intent that motivated the statute and apply it to the new circumstance at hand. Others reject this advice, arguing that legislative intent cannot exist.

A set of abstract formal models of collective decision-making plays an important role in this debate. Here, we evaluate arguments against legislative intent that are based on these models. The models come from a branch of cooperative game theory called social choice theory. ${ }^{2}$

Cooperative game theory uses clearly stated assumptions and formal logic to clarify relationships between individual preferences and collective choices. It is the oldest brand of game theory. Unlike the kind of game theory (non-cooperative) used by most social scientists today, cooperative game theory does not allow individual actors to adapt

1. See, e.g., WLlliam Eskridge, JR., Dynamic STATUTORY INTERPRETATION (1994); Mathew D. McCubbins \& Daniel B. Rodriguez, Theories of Law and Statutory Interpretation, in What StatuTes MEan (Mathew D. McCubbins \& Daniel B. Rodriguez eds., 2004).

2. In a companion paper, Arthur Lupia \& Mathew D. McCubbins, When Can Legislative Records Aid Statutory Interpretation? Inference, Credibility, and Collective Intent in the United States Congress, in WHAT STATUTES MEAN (Mathew D. McCubbins \& Daniel B. Rodriguez eds., 2004), we focus on a second class of models cited in these arguments: the branch of non-cooperative game theory that examines legislative decision making. 
strategically to their environment. It also ignores the time and effort required to make and implement collective decisions. We will show that factors such as these make cooperative game theory a weak and unreliable foundation for arguments against legislative intent.

While cooperative game theory is seen less frequently at the cutting edge of social science today, its legacy is of fundamental importance. The branch known as social choice theory remains particularly influential. Scholars such as Arrow $^{3}$ and $\mathrm{Sen}^{4}$ won Nobel Prizes by using the method to clarify what groups of people can and cannot accomplish when choosing collectively. ${ }^{5}$ Scholars such as McKelvey ${ }^{6}$ and Schofield ${ }^{7}$ applied analogous logic to majority decisions in political contexts. ${ }^{8}$

3. Kenneth, J. ARrow, Social Choice and Individual Values (2d ed. 1963).

4. Amartya Sen, Social Choice Theory: A Re-Examination, 45 ECONOMETRICA 53 (1977); Amartya Sen, Collective Choice and Social Welfare (1970).

5. See, e.g., Peter Bernholz, Logrolling, Arrow Paradox and Cyclical Majorities, 15 Public Choice 87 (1973); Otto A. Davis, Morris H. DeGroot \& Melvin Hinich, Social Preference Orderings and the Majority Rule, 40 ECONOMETRICA 147 (1972); James M. Enelow \& Melvin J. Hinich, On Plott's Pairwise Symmetry Condition for Majority Rule Equilibrium, 40 PUBLIC CHOICE 317 (1983); Allan Gibbard, Manipulation of Voting Schemes: A General Result, 41 ECONOMETRICA 587 (1973); Bernard Grofman, Some Notes on Voting Schemes and the Will of the Majority, 7 PUBLIC CHOICE 65 (1969); Charles R. Plott, A Notion of Equilibrium and Its Possibility Under Majority Rule, 57 AM. ECON. REv. 787 (1967); Thomas Schwartz, No Minimally Reasonable CollectiveChoice Process Can Be Strategy Proof, 3 Mathematical Social Science 57 (1982); Judith Sloss, Stable Outcomes in Majority Rule Voting Games, 15 PUBLIC CHOICE 19 (1973); Mark A. Satterthwaite, Strategy-Proofness and Arrow's Conditions: Existence and Correspondence Theorems for Voting Procedures and Social Welfare Functions, 13 J. ECON. THEORY 187 (1975).

6. Richard D. McKelvey, Intransitivities in Multidimensional Voting Models and Some Implications for Agenda Control, 12 J. ECON. THEORY 472 (1976).

7. Norman Schofield, Instability of Simple Dynamic Games, 45 THE REVIEW OF ECONOMIC STUDIES 574 (1978); Norman Schofield, Generic Instability of Majority Rule, 50 The ReVIEW OF ECONOMiC Studies 695 (1983).

8. See also Linda Cohen, Cyclical Sets in Multidimensional Voting Models, $20 \mathrm{~J}$. ECON. THEORY 1 (1979); Thomas Schwartz, On the Possibility of Rational Policy Evaluation, 1 THEORY AND DECISION 89 (1970); and Steven Slutsky, Equilibrium Under "Majority Voting", 47 ECONOMETRICA 1113 (1979), for related spatial instability results. In these and other social choice theories, decision-makers are non-strategic. Because social choice theory's focus is on the aggregative properties of collective choice rules, it is simpler to portray decision makers as voting for their most preferred alternative even if they could benefit by misrepresenting their preferences in the act of voting. While social choice theorists have, in fact, proven that all such rules have strategy-inducing properties, for example, Allan Gibbard, Manipulation of Voting Schemes: A General Result, 41 ECONOMETRICA 587 (1973); and Mark A. Satterthwaite, Strategy-Proofness 
Work such as this reveals the dangers of ascribing desirable normative attributes such as "the will of the majority" to collective decisions.

Given the main theme of social choice theory's most influential findings, it is not surprising that learned observers try to apply the results against legislative intent. Shepsle, for example, uses this literature to conclude, "Legislative intent is an internally inconsistent, self-contradictory expression." Mashaw concurs: "[T] he outcomes of collective decisions are probably meaningless because it is impossible to be certain that they are not simply an artifact of the decision process that has been used." 10

In what follows, we examine the connection between social choice theory and statutory interpretation. We find a considerable gap between what social choice theory proves and prominent claims made against legislative intent on the theory's behalf. Important aspects of the theory are "lost in translation." While oft-cited social choice theory results can make it difficult to ascribe collective intent to legislative choice, you must misapply or misread these results to conclude that they render all such ascriptions meaningless.

Our argument has two parts. First, we focus on claims against legislative intent that are based on Arrow's General Possibility Theorem. Arrow's Theorem is a precise mathematical claim supported by a concise proof. We demonstrate a considerable gap between what Arrow proved and claims made about his result by participants in the legislative intent debate. While Arrow's Theorem is an important social scientific finding, its implication for legislative intent has been exaggerated.

Then, we focus on claims against legislative intent stemming from social choice theory's majority rule voting results. This work shows that legislative procedures can greatly affect the relationship between what individuals want and what groups do. This literature is also misapplied against legislative intent. Here, the problem lies in authors' failures to recognize that the theoretical conclusions depend on clearly stated, but wildly unrealistic, assumptions about human decision making - assumptions such as "voters are never uncertain about the consequences of their actions" and "legislators have infinite resources for changing law and policy." We demonstrate that adding more realistic assumptions yields

and Arrow's Conditions: Existence and Correspondence Theorems for Voting Procedures and Social Welfare Functions, 13 J. ECON. THEORY 187 (1975), actually endogenizing strategic decision making into studies of collective choice falls in the domain of noncooperative game theory.

9. Kenneth A. Shepsle, Congress Is a "They" Not an "It": Legislative Intent as Oxymoron, 12 INT'L REV. LAW \& ECON. 239, 239 (1992).

10. Jerry L. Mashaw, The Economics of Politics and the Understanding of Public Law, 65 CHI.-KENT L. ReV. 123, 126-27 (1989). 
very different theoretical results-including ones that allow analysts to draw meaningful inferences about legislative intent.

In sum, we reveal a substantial difference between the conclusions and proofs of social choice theory and the claims made about them in the legislative intent debate. We find that more accurate translations are insufficient to render legislative intent meaningless.

\section{IIII. RIGHT ARROW, WRONG TARgET}

In their challenge to the applicability of the "legal model," Segal and Spaeth make the following claim, "It is well established, via mathematical proofs, that every method of social or collective choice- every arrangement whereby individual choices are pooled to arrive at a collective decision - violates at least one principle required for reasonable and fair democratic decision making." 11

The result to which they are referring is Arrow's General Possibility Theorem. It is the same result to which Shepsle refers when he claims, "In the context of majority rule voting, [Arrow's] [T] heorem implies that it is not possible to guarantee that a majority rule process will yield coherent choices." ${ }^{\prime 2}$ In the article whose subtitle is Legislative Intent as Oxymoron, Shepsle further suggests that this "incoherence will often take the form of the nonexistence of a collectively 'best' alternative."13 The result is often cited in this vein, with Niemi and Pildes' description being representative: "Arrow's Theorem reveals that, in theory, public decision making processes cannot be designed in ways that are fair and that preclude the possibility that decisions will cycle among various options (at least under conditions of significant social conflict)."1/4

Such claims have several things in common. They are made against legislative intent. They are based on Arrow's Theorem. And in all cases, important parts of the theorem are "lost in translation." Arrow proved none of these claims.

Arrow's Theorem provides a fundamental insight about collective

11. Jefrrey A. Segal \& Harold J. Spaeth, The Supreme Court and the ATtitudinAL MODEl 62 (1993).

12. Kenneth A. Shepsle, Congress Is a "They" Not an "It": Legislative Intent as Oxymoron, 12 INT'L REV. LAW \& ECON. 239, 241 (1992).

13. Id.

14. Richard H. Pildes \& Richard G. Niemi, Expressive Harms, "Bizarre Districts," and Voting Rights: Evaluating Election-District Appearances After Shaw v. Reno, $92 \mathrm{MICH}$. L. REV. 483, 505 n.88 (1993). 
decision making: when at least two individuals use a collective choice rule (e.g., a voting rule) to choose winners from a set of at least three alternatives, certain normative goals are impossible to accomplish. But what did he actually prove impossible?

Arrow's Theorem focuses on potential attributes of a collective choice rule (a.k.a., a social welfare function; henceforth, a CCR). A CCR converts a set of individual preference orderings, called a preference profile $P$, into a social ordering (e.g., a set of winning choices). ${ }^{15}$ For example, the method of majority decision (hereafter, MMD) is a CCR where alternative $a$ is chosen over alternative $b$ if and only if more people prefer $a$ to $b$ than prefer $b$ to $a$. So, if there are three individuals, and if the preference profile $P$ consists of the three individual preference orderings such that "individual 1 prefers $x$ to $y$ to $z$, individual 2 prefers $y$ to $z$ to $x$, and individual 3 prefers $x$ to $z$ to $y$," then the CCR generates the outcome $x$ when it is paired against alternatives $y$ and/or $z$ and generates the outcome $y$ when it is paired against $z$ alone.

Arrow's Theorem lists a set of conditions that a CCR can satisfy (i.e., attributes that a CCR can have). One of Arrow's conditions prevents any individual from being a dictator (i.e., from getting what they want despite how everyone else votes). Another says that if all people strictly prefer an alternative $x$ to an alternative $y$, then if it is possible to have multiple winners and $y$ is a winner, then $x$ must be a winner, as well.

A third condition, Arrow's condition 1', is important when considering the Possibility Theorem's applicability to questions of statutory interpretation. The condition is satisfied if the CCR's domain extends to all logically possible preference profiles. Sen refers to this condition as "Unrestricted Domain" and describes it as follows:

[A]s a method of going from individual preferences to social preference, the [CCR] must be wide enough in scope to work from any logically possible set of individual orderings. Consider, for example, the Pareto principle as a choice rule. It gives a perfectly fine social ordering if the individual preferences are unanimous. . [b]ut it will not yield a social ordering in other situations...This requirement that the rule must work for every logically possible configuration of the individual preference orderings we shall call the condition of unrestricted domain. ${ }^{16}$

Note here that what constitutes a violation of unrestricted domain is the existence of a single preference profile that when entered as input into a

15. We follow the usual social choice theory convention and assume that individual preferences are proper orderings in the sense that they are complete, reflexive, and transitive. For a further explanation, see Amartya SEN, Collective Choice AND SOCIAL WELFARE 1-20 (1970).

16. Amartya Sen, Collective Choice and Social Welfare 37 (1970). 
collective choice rule, yields no social decision. Moreover, it is sufficient that the preference profile be logically possible. As a result, the violating profile might not be one that we would ever expect to see (e.g., a logically possible preference profile in a legislative example is one where each member of a legislature prefers a collective choice outcome that causes them to endure the worst torture they can imagine over every other policy they could pass). The condition is considered violated even though the sole condition-violating preference profile is strictly hypothetical and other preference profiles-including ones that we might judge both logically possible and likely to be seen - satisfy the condition.

It is important to note that Arrow's list of conditions is not a complete list of all the desirable attributes that a method of social choice might have. It is a very short list. A key advantage of the list, however, is that Arrow states each condition in stark and clear mathematical terms. As a result, his theorem is a strong and precise statement about the conditions under which a CCR can have this particular set of attributes.

While Arrow's list contains a few other conditions, we will not describe them in detail here as the information we have already provided is sufficient to support our main conclusion-that Arrow's Theorem is insufficient to support broad claims against legislative intent. ${ }^{17}$ The argument is as follows:

Let $M$ be the number of conditions besides unrestricted domain that Arrow raised and let $N$ be the number of preference profiles. Seen this way, Arrow proved the following: a collective choice rule can satisfy all of the $M$ criteria simultaneously for at most $N-1$ of the preference profiles. An alternative way to interpret the result is that we can satisfy no more than $M-1$ of Arrow's other criteria simultaneously if we want to insist on Unrestricted Domain (the CCR yields a social ordering for all $N$ preference profiles).

This is what Arrow proves.

When the theorem is used in legislative intent debates as the sole basis for claiming that legislative intent has no meaning, the criterion for "having meaning" is satisfying Arrow's criteria. One can argue with the notion that Arrow's criteria are the only possible normative or logical foundations for legislative intent. However, we argue that even using these criteria, Arrow's Theorem is insufficient to render legislative intent

17. For readers who are interested in specific details of Arrow's conditions see KENNETH, J. ARROW, SOCIAL ChOICE AND INDIVIDUAL VALUES (2d ed. 1963) or AMARTYA SEn, Collective Choice And Social Welfare 41-51 (1970). 
meaningless or an oxymoron.

Consider Shepsle's argument. It is clearly presented and we agree with many of the points he makes. However, we disagree with several claims he makes about what Arrow's Theorem implies for legislative intent in the section entitled "The Arrowian Dilemma."18

The words "not possible to guarantee" in the claim "[Arrow's] Theorem implies that it is not possible to guarantee that a majority rule process will yield coherent choices" ${ }^{19}$ reflects the attributes of Arrow's theorem just described-no $C C R$ can guarantee the satisfaction of all $M$ conditions for all $N$ preference profiles, but, of course, it may be able to make such a guarantee for $N-I$ preference profiles. Shepsle continues:

Put differently, if the preferences of the members of a voting body display a modicum of diversity, then majority voting need not generate a transitive ordering of the alternatives available for choice; the alternatives cycle...Indeed, incoherence will often take the form of the nonexistence of a collectively "best" alternative. ${ }^{20}$

In this claim, coherence and transitivity are equated. Transitivity is indeed one of the criteria Arrow poses where transitivity is defined as follows-if $x$ is at least as good as $y$ and $y$ is at least as good as $z$, then $x$ is at least as good as $z$. And it is true that if one wants a CCR to satisfy all of the other $M$ criteria for all possible preference profiles, then Arrow proves that transitivity, and by implication coherence, must be sacrificed. But this kind of argument can be made about any of Arrow's conditions--not just transitivity. If you want to satisfy all but one of the $M$ criteria for all possible preference profiles, then the remaining condition must be sacrificed.

By implication, Arrow's Theorem allows transitivity even in the presence of preference diversity. If, for example, you sacrifice Universal Domain (i.e., you require only that Arrow's criteria be satisfied for up to $N-I$ preference profiles), then you need not sacrifice any of the $M-l$ other criteria to get transitivity. Alternatively, if you must have Universal

18. Kenneth A. Shepsle, Congress Is a "They" Not an "It": Legislative Intent as Oxymoron, 12 INT'L REV. LAW \& ECON. 239, $241-49$ (1992). Subsequent parts of the section draw on majority rule instability claims from cooperative game theory (which we address in the next section of this article) and other sources including research on Congress and non-cooperative game theory (which we address in Arthur Lupia \& Mathew D. McCubbins, When Can Legislative Records Aid Statutory Interpretation? Inference, Credibility, and Collective Intent in the United States Congress, in WHAT STATUTES MEAN (Mathew D. McCubbins \& Daniel B. Rodriguez eds., 2004))

19. Kenneth A. Shepsle, Congress Is a "They" Not an "It": Legislative Intent as Oxymoron, 12 INT'L REV. LAW \& ECON. 239, 241 (1992).

20. Id. 
Domain, then you can achieve transitivity by giving up just one of the M-1 other criteria. Thus, Arrow does not prove that a modicum of preference diversity is sufficient to cause incoherence.

Shepsle then suggests that this "incoherence will often take the form of the nonexistence of a collectively 'best' alternative."21 However, aside from the existence claim described above, Arrow's Theorem and proof ${ }^{22}$ say nothing about the frequency of intransitivity - or the frequency of any of his other criteria for that matter. Beyond the fact that for at least one preference profile per CCR the $M$ criteria will not be satisfied simultaneously, Arrow's Theorem is completely silent on the matter of frequency. Beyond existence, Arrow's Theorem offers no insight about the frequency of incoherence or any other normative violation.

Our disagreement with other claims about Arrow's Theorem and legislative intent is more nuanced. Recall, for example, Segal and Spaeth's claim, "It is well established, via mathematical proofs, that every method of social or collective choice-every arrangement whereby individual choices are pooled to arrive at a collective decision-violates at least one principle required for reasonable and fair democratic decision making." ${ }^{23}$

What Arrow proves is that no $\mathrm{CCR}$ can satisfy the $M$ criteria simultaneously for more than $N-1$ of the $N$ possible preference profiles. In other words, Arrow proves a violation of one of the $M$ criteria for only a single preference profile per $C C R$ - he does not prove that violations occur for every preference profile. Indeed, the Theorem and the proof are silent about how many such violating profiles there may be. Moreover, it is trivial to create examples where for a large set of CCR's and a large number of preference profiles, all $M$ criteria are satisfied (e.g., When there are hundreds of legislators and dozens of alternatives, the number of logically possible preference profiles can be in the millions. Arrow's Theorem allows all $M$ criteria to be satisfied for all but one of these profiles).

In other words, Arrow's Theorem is sufficient to prove Segal and Spaeth's claim only if we categorize each of Arrow's conditions, including Unrestricted Domain, as a "principle required for reasonable

21. Id. (emphais added).

22. KenNeth, J. ARrow, Social Choice and Individual Values 97-100 (2d ed. 1963).

23. JeFrRey A. SEgal \& HAROLd J. SPAETH, THE SUPREME COURT AND THE ATtTUUdNAL MODEL 62 (1993). 
and fair democratic decision making." 24 If, however, we consider "fair and reasonable" CCR's that satisfy Arrow's $M$ criteria up to $N-I$ logically possible preference profiles, or if we agree to restrict attention to preference profiles that are both "logically possible" and "have a greater than zero chance of being observed given what we know about individual preferences," then the Theorem is insufficient to support the claim.

In sum, Arrow's Theorem is a powerful and important piece of social science, but it does not prove all claims against legislative intent made in its name. The result renders only a very limited set of normative statements about CCR's impossible - even he called it a "General Possibility Theorem." The proof does not show that any particular condition can never be satisfied nor does it preclude "fair" decision making unless you equate fairness with Arrow's short list of conditions. As described above, the proof allows almost every combination of Arrow's conditions to be achieved simultaneously for almost every possible preference profile for any CCR. This is why reading any of the validated proofs of Arrow's Theorem will quickly reveal that Arrow proved something far short of the universal impossibilities often claimed in the Theorem's name.

\section{LOST IN APPLICATION: THE MAJORITY RULE INSTABILITY RESULTS}

Other participants in statutory interpretation debates cite social choice theory, but not Arrow's Theorem. They focus on social choice theory's majority rule results. One such result is Condorcet's famous paradox. ${ }^{25}$ There are three alternatives, and the CCR is a two-stage agenda: Using MMD, first pit two alternatives against each other and then put the winner up against the third. Condorcet's paradox is as follows. Consider the preference profile "individual 1 prefers $x$ to $y$ to $z, 2$ prefers $y$ to $z$ to $x$, and 3 prefers $z$ to $x$ to $y$." If the MMD agenda is used " $x$ versus $y$, winner versus $z$ " $z$ is the winner because $x$ beats $y$ by 2 votes to 1 in the first vote and $z$ beats $x$ by the same margin in the second vote. If, however, a different agenda is used, a different winner emerges. The paradox is that even though preferences remain constant, any alternative can win - " $x$ versus $z$, winner versus $y$ " produces $y$ as the winner and " $y$ versus $z$, winner versus $x$ " makes $x$ victorious. In other words, simply manipulating the order in which alternatives are voted on is sufficient to lead a majority to make contradictory choices. In an even more disquieting result, McKelvey showed that social choices made by

24. Id.

25. MARQUIS DE CONDORCET, ESSAI SUR L'APPLICATION DE L'ANALYSE A LA Probabilté des Decisions Rendues a la PluRalité des VolX (1785). 
majority rule can become wildly unrepresentative of any voter's preferences (i.e, he proved that a series of majority votes can result in the selection of an alternative $\mathrm{X}$ instead of an alternative $\mathrm{Y}$ even though all voters prefer $\mathrm{Y}$ to $\mathrm{X}) .^{26}$

Such results have led scholars to conclude that "the choices of majorities do not automatically display desirable normative principles"27 and that the final outcome of legislative deliberations "may be arbitrary." 28 Farber reports that they have also affected the legal literature and judicial norms of statutory interpretation, "This seems to make it questionable to say that any particular outcome reflects the preferences of the legislators ... There is an inescapable chaos to collective decision making - vox populi, it would seem, cannot carry a tune."29

Do social choice theory's majority rule results prove that it is impossible to draw meaningful inferences about collective intent from majority decisions? To answer this question, we take a closer look at the underlying scholarship.

The Condorcet and McKelvey results are part of a class of instability results. Stability is an important concept in the study of social choice. It refers to the relationship between individual preferences and collective choices. If a set of individual preferences always yields a particular collective choice, then the relationship between preferences and outcomes is stable. If, however, a set of individual preferences corresponds to no particular collective choice, then the relationship is unstable. Condorcet's paradox, explained above, is an example of an unstable relationship - a single preference profile yields three very different social choices.

When a preference-outcome relation is unstable, it can be difficult or impossible to deduce what any individual or set of individuals wanted from the choice that they made as a group. This is why instability results appear useful to arguments against legislative intent-it is difficult to assign intent to a collective that can produce very different choices even though its members' preferences remain constant.

26. Richard D. McKelvey, Intransitivities in Multidimensional Voting Models and Some Implications for Agenda Control, 12 J. ECON. THEORY 472 (1976).

27. William H. Riker \& Barry W. Weingast, Constitutional Regulation of Legislative Choice: The Political Consequences of Judicial Deference to Legislatures, 74 VA. L. REV. 373, 386 (1988).

28. Kenneth A. Shepsle, Congress Is a "They" Not an "It": Legislative Intent as Oxymoron, 12 INT'L REV. LAW \& ECON. 239, 241-42 (1992).

29. Daniel A. Farber, Positive Theory as Normative Critique, 68 S. CAL. L. Rev. 1565,1577 (1995). 
A focal reference for scholars who attempt to tie the instability results to legislative intent is a debate featuring Riker and Shepsle. In 1980, Riker chose the term "disequilibrium" to describe the unstable relationship between individual preferences and social choice. He concluded that "Disequilibrium, or the potential that the status quo be upset, is the characteristic feature of politics." ${ }^{30} \mathrm{He}$ went on to argue that "politics is the dismal science because we have learned from it that there are no fundamental equilibria to predict. In the absence of such equilibria we cannot know much about the future at all. .." 31

Shepsle ${ }^{32}$ and Shepsle and Weingast ${ }^{33}$ counterargued that social choice theory ignored the context in which actual social choices occur. They then added a context of rules and procedure to the standard social choice theory framework and found stable correspondences between preferences and choices. They conclude that institutions induce stability. As Shepsle states, "institutional structure-in the form of rules of jurisdiction and amendment control--has an important independent impact on the existence of equilibrium and, together with the distribution of preferences, codetermines the characteristics of the equilibrium state(s) of collective choice processes." ${ }^{34}$ To Shepsle and Weingast, institutions induce stability by reducing the number of elements in the decision makers' choice set. ${ }^{35}$ With fewer items to choose from, there are fewer challengers to the policy status quo and with fewer challengers, there is more stability. Thus, Shepsle and Weingast answered Tullock's empirically-motivated question "Why so much stability?" 36 with the response "Institutional arrangements do it!" 37

30. William H. Riker, Implications from the Disequilibrium of Majority Rule for the Study of Institutions, 74 AM. POL. SCI. REV. 432, 443 (1980).

31. Id.

32. Kenneth A. Shepsle, Institutional Arrangements and Equilibrium in Multidimensional Voting Models, 23 AM. J. POL. SCI. 27 (1979).

33. Kenneth A. Shepsle \& Barry R. Weingast, Structure-Induced Equilibrium and Legislative Choice, 37 PUBLIC CHOICE 503 (1981).

34. Kenneth A. Shepsle, Institutional Arrangements and Equilibrium in Multidimensional Voting Models, 23 AM. J. POL. SCI. 27, 29 (1979).

35. Shepsle defined a structure-induced equilibrium as an alternative that is "invulnerable in the sense that no other alternative, allowed by the rules of procedure, is preferred by all the individuals, structural units, and coalitions that possess distinctive veto or voting power." Kenneth A. Shepsle, Studying Institutions: Some Lessons from the Rational Choice Approach, 1 J. THEORETICAL POL. 131, 137 (1989). He has also discussed some sources of institutional stability such as the high costs of change, but has recognized that theorists have "just begun to tackle the problem of institutional robustness." Id. at 143.

36. Gordon Tullock, Why So Much Stability, 37 Public Choice 189 (1981).

37. Kenneth A. Shepsle \& Barry R. Weingast, Structure-Induced Equilibrium and Legislative Choice, 37 PUBLIC CHOICE 503, 504 (1981). 
Riker replied that groups choose institutions. He continued that if institutional choice is but one example of collective choice, then institutional choice is subject to all the same instability problems as collective choice more generally. As Riker notes, "the losers are likely to want to change the committees and jurisdictions in the hope of winning on another day. In the end, therefore, institutions are no more than rules and rules are themselves the product of social decisions. Consequently, the rules are also not in equilibrium." 38

Put another way, people choose institutions and if they understand that certain institutions correspond to certain collective choices, then the choice of institutions can be just as unstable as any other collective choice. Therefore, one cannot claim to have found a stable relationship between preferences and choice if the institutions that are alleged to induce stability are themselves the product of collective choice. Riker's conclusion implies that the claim "Institutional arrangements do it" begs, rather than answers, the question "Why so much stability?"39

We contend that instability is not as endemic as Riker alleges and we shall support this conclusion in a manner that does not beg Riker's

38. William H. Riker, Implications from the Disequilibrium of Majority Rule for the Study of Institutions, 74 AM. POL. SCI. REV. 432, 444-45 (1980).

39. Other scholars, most notably Judith Sloss, Stable Outcomes in Majority Rule Voting Games, 15 PuBlic CHOICE 19 (1973), have used the transaction cost logic of R.H. Coase, The Nature of the Firm, 4 ECONOMICA 386 (1937); DOUGlass C. NORTH, THE Structure and Change of Economic History (1981); and Oliver E. Williamson, MARKETS AND HIERARCHIES: ANALYSIS AND ANTITRUST IMPLICATIONS (1975) to argue that many institutional, jurisdictional, and partisan arrangements induce stability by making change costly or impossible. $C f$., John $\mathrm{H}$. Aldrich, A Model of a Legislature with Two Parties and a Committee System, 19 LEGIS. STUD. Q. 313 (1994); Gary W. Cox \& Mathew D. McCubbins, Bonding, Structure, and the Stability of Political Parties: Party Government in the House, 19 LEGIS. STUD. Q. 215 (1994); Douglass Dion, The Robustness of the Structure-Induced Equilibrium, 36 AM. J. POL. SCI. 462 (1992); Gary J. Miller \& Thomas H. Hammond, Committees and the Core of the Constitution, 66 PUBLIC CHOICE 201 (1990); Peter C. Ordeshook, Political Disequilibrium and Scientific Inquiry: A Comment on William Riker's "Implications from the Disequilibrium of Majority Rule for the Study of Institutions", 74 AM. POL. SCI. REv. 447 (1980); Kenneth A. Shepsle, Prospects for Formal Models of Legislatures, 10 LEGIS. STUD. Q. 5 (1985); Kenneth A. Shepsle, Institutional Equilibrium and Equilibrium in Institutions, in POLITICAL SCIENCE: The SCIENCE OF Politics 51 (Herbert Weisberg ed., 1986); Gordon Tullock, Why No Cycles, 28 ATLANTIC ECON. J. 1 (2000); Barry R. Weingast \& William J. Marshall, The Industrial Organization of Congress, 96 THE JouRnal OF POLITICAL ECONOMY 132 (1988). However, each of these arrangements is, itself, a product of collective choice. So, such arguments, while compelling for other reasons, do not escape Riker's counterargument. 
question. Moreover, to the extent that analysts equate instability and the impossibility of legislative intent, our argument brings the possibility of legislative intent back to life. We begin by accepting Riker's key premise: if one wants to claim that a particular relationship between individual preferences and collective choices is stable, then the origin of social choice stability must be out of the reach of human manipulation. It must be exogenous - the stability cannot be the product of another collective choice. To this end, we introduce the notion that certain exogenous forces, such as systematic and universal limits on human energy, cognition, and communicative ability, may bring about stability because they impose high costs on individuals and groups who may otherwise have an incentive to change a social choice.

Our main finding in this section reengages Riker and Shepsle's debate about the origins of stability. Riker, in his counterargument to Shepsle, assumes that all of the means for inducing stability are endogenous; that is, they are all prior choices made by the collectivity itself. By contrast, we argue that systematic, universal, and exogenous forces of nature drain people of their desire or ability to destabilize standing social decisions. We then find that disequilibrium, or the potential that the status quo be upset, is not the characteristic feature of politics-even in the absence of institutions. As a result, we conclude that social choice theory's instability results are not sufficient to prove that the impossibility of legislative intent.

We proceed as follows. First, we provide concepts and notation essential to understanding just what the instability results prove. Then, we amend the social choice framework to incorporate some of the exogenous forces described above. In each case, the force yields stability.

\section{A. The Basic Framework of Social Choice Theory}

There are three basic elements of any social choice problem: the set of alternatives (e.g., $\{x, y, z\} \in S$ ), the set of individual preferences, and the collective choice rule. ${ }^{40}$ Because social choice theory is a branch of

40. In what follows, we present only the elements of social choice theory that are necessary to make our point about stability. See KENNETH, J. ARrow, Social Choice AND Individual Values (2d ed. 1963); AMARTYA SEN, Collective Choice AND SOCIAL Welfare 1-20 (1970); Kotaro Suzumura, Rational Choice, Collective Decisions, and Social Welfare (1983); Thomas Schwartz, The Logic of Collective Choice (1986); and Herve Moulin, Axioms of Cooperative Decision Making (1988) for more thorough treatments. Also note that choice sets, the typical output of a collective choice rule, can have more than one element. To simplify the exposition, we describe examples whose choice sets have only one element. 
cooperative game theory, the alternatives are treated as common knowledge endstates. That is all players base their votes on the knowledge that if the group chooses alternative $x$, then $x$ will be the sole determinant of each person's well being. Treating alternatives as endstates allows us to place them into preference orderings and preference profiles. As mentioned in the section on Arrow's Theorem, a collective choice rule translates the set of individual preference orderings, and the preference profile $P$, into a collective choice.

So, when is a collective choice $x \in S$ stable? Let $D(g, x, y)$ refer to alternatives $x \in S$ and $y \in S$ and a group of individuals, $g$, who, once $x$ is chosen, together have the ability and desire to overturn $x$ in favor of $y$. Whether these individuals gain their power from a previously chosen $\mathrm{CCR}$ or the state of nature is irrelevant. Then, let $y D x$ mean that $D(g, x$, $y$ ) holds for some group $g$. Then $x \in S$ is stable if and only if there is no $y \in S$ for which $y D x .^{41}$ So, given an MMD agenda of the form " $x$ versus $y$, winner versus $z$," we say that an outcome $x$ is stable if no such agenda yields a different outcome. If, by contrast, we re-introduce the preference profile of Condorcet's paradox ${ }^{42}$ then there is no stable outcome. This is so because any alternative can lose a majority vote to one of the other alternatives - $x$ can lose to $z, z$ can lose to $y$, and $y$ can lose to $x$.

The basic elements just described are the foundation of social choice theory's most famous instability results. ${ }^{43}$ Take, for example, McKelvey's result, which is derived from a standard spatial model of policy choice. In it, a group of individuals chooses from a set of alternatives, where each alternative is defined as a point in the two-dimensional space $S$.

41. This definition, and the language that motivates it, follows THOMAS SCHWARTZ, ThE MEANING OF INSTABLITY 13-14 (1986) (typescript: University of Texas).

42. See supra note 25.

43. E.g., C.L. Dodgson, a Method of Taking Votes on More Than Two Issues (1876); E. J. Nanson, Methods of Election, 18 TRANSACtions AND PROCEEDINGS OF THE ROYAL SOCIETY OF VICTORIA 197 (1882); William H. Riker, Voting and the Summation of Preferences: An Interpretive Bibliographic Review of Selected Developments during the Last Decade, 55 AM. POL. SCI. ReV. 900 (1961); Charles R. Plott, A Notion of Equilibrium and Its Possibility Under Majority Rule, 57 AM. ECON. REv. 787 (1967); Thomas Schwartz, Votes, Strategies, and Institutions: An Introduction to the Theory of Collective Choice, in CONGRESS: STRUCTURE AND POLICY (Mathew D. McCubbins \& Terry Sullivan eds., 1987); Richard D. McKelvey, Intransitivities in Multidimensional Voting Models and Some Implications for Agenda Control, 12 J. ECON. THEORY 472 (1976); Linda Cohen, Cyclical Sets in Multidimensional Voting Models, 20 J. ECON. THEORY 1 (1979); Norman Schofield, Generic Instability of Majority Rule, 50 THE REVIEW OF ECONOMIC STUDIES 695 (1983). 
Individual preferences are also represented by ideal points in this space. When the exogenous agenda setter in McKelvey's model proposes that the group hold a vote on whether to change policy, the group does so without hesitation. Each individual can vote for the status quo (hereafter, $q$ ), or an alternative (hereafter, $x$ ) and chooses whichever of $q$ or $x$ is closest to her ideal point. The majority winner becomes the status quo and the sequence begins again. In such environs, McKelvey proves that if enough votes are taken, an agenda can be constructed in which any point in $S$ can win a majority vote-including alternatives that are very far from all voters' ideal points. This result, moreover, is achieved without altering a single voter's preferences-which makes it a classic instability result.

However, models such as this not only "stack the deck" towards instability (rather than stability) results; they also complicate attempts to export the results to real voting contexts. In them, the only barrier to moving from one collective choice to another is that the challenging alternative be a possible outcome of the CCR. There are no difficulties involved in "holding another vote" or "implementing a different policy." These models include no scarcity of the type that makes holding another vote or implementing a new policy expensive. ${ }^{44}$ These models also assume that all individuals choose as if all of the alternatives have welfare-enhancing properties of all the alternatives. There is no complexity to make people uncertain about the consequences of their actions or hesitant about change.

Given these assumptions, it is not at all surprising that the theories in question produce instability results-these theories assume that change is free and easy. Or, as Easterbrook argues:

Perhaps... the problem inheres in a model in which actors try to maximize something (the achievement of their own objectives) but in which there are no scarcities. What is the constraint? How does a need to conserve on some scarce good drive people to an equilibrium?... Information is one candidate for scarcity. Time is another.... ${ }^{45}$

He concludes that the literature cited above "needs a theory of scarcity." 46 We agree. Scarcity and uncertainty are our constant companions; they are ubiquitous features of the human existence. Scarcity in human time, energy, and ability makes change anything but free. And uncertainty, which implies

44. A notable exception to this practice is Judith Sloss, Stable Outcomes in Majority Rule Voting Games, 15 PUBLIC CHOICE 19 (1973). We discuss the relationship between her approach and our own later in the paper.

45. Frank H. Easterbrook, Some Tasks in Understanding Law Through the Lens of Public Choice, 12 INT'L REV. L. \& ECON. 284, 285 (1992).

46. Id. at 286. 
that we cannot know the consequences of our actions, may drain us of the desire for change.

Indeed, to destabilize a standing social decision, a group of individuals must have both the ability and the desire to force a change. Scarcity and uncertainty can drain them of both. When scarcity and uncertainty are the product of exogenous forces and induce people to stick with particular choices, they induce stability. Moreover, these forces shape the ways people think about what they are doing. Therefore, they help to define people's intent. And when scarcity and uncertainty have common influences on a group of people, important aspects of their intent may be shared. Therefore, when scarcity and uncertainty induce stability, it is not impossible to conclude that the social choice is a product of collective intent.

\section{B. Increasing Social Choice Theory's Applicability}

We now propose three amendments to the class of models described above. Each one incorporates exogenous forces of nature-forces that engender the scarcity and uncertainty described above-into social choice theory's logical structure.

\section{Amendment: Include Exogenous Decision Costs and Give the Status Quo Special Treatment}

Changing policy requires time and effort. Time and effort are scarce. Opinions must be gathered, strategies must be expressed, proposals must be written and collected, and votes must be held. More important, attempting to change one policy may entail the payment of substantial opportunity costs - the forfeited opportunity to do something else. When such costs are considered, changing some policy may require more time and effort than a collectivity can muster.

Exogenous forces (i.e., nature) create some of these costs-in effect influencing the amount of effort that certain changes require and restricting the range of activities in which people can engage. For example, humans have limited perceptual capabilities (i.e., eyes that can see only so far, ears that can hear only so much).$^{47}$ Decision making also requires attention, which, in turn, requires energy (e.g., you cannot read this article or pay

47. See also Herbert A. Simon, Theories of Decision-Making in Economics and Behavioral Science, 49 AM. ECON. REV. 253 (1959); HeRBERT A. SimON, MODELS OF THOUGHT (1979). 
attention to what a friend is saying without exerting effort). Limited perception and limited energy combine to make certain prerequisites for policy change (e.g., attention to complicated alternatives) costly or impossible. For example, we sometimes ignore new ideas, even when their adoption may be beneficial--because we are too distracted by other things. Moreover, limits in the human ability to communicate and receive communication make some ideas difficult or impossible to express, as writers who attempt to make technical arguments to non-technical audiences understand well.

Even when people are paying attention and the ideas implicit in a policy change can be expressed, collective decisions often require additional effort. For example, a person who wants to challenge the status quo may have to persuade others that accepting the proposal is better than staying with the status quo. As psychologists, economists, and political scientists know, however, persuasion is often difficult and sometimes impossible. ${ }^{48}$

Together, limited energy, limited perception, cognitive processing limits (e.g., memory) and the difficulties inherent in communication and persuasion increase the costs of many forms of policy change and make some forms of policy change impossible. To put these ideas into the language of social choice theory, let $P_{i}$ be the part of preference profile $P$ that pertains to an individual $i$ 's preferences. Let $K_{i}$ be individual $i$ 's exogenous decision costs-the personal cost of participating in a single attempt to challenge some aspect of the status quo. ${ }^{49}$ Let $P(K)$ be the preference profile after everyone's decision costs are introduced and let $P_{i}\left(K_{i}\right)$ be the part of this profile that pertains to individual $i$.

We demonstrate the effects of such costs on a collective choice in a series of figures. In the figures, the status quo, $q$, is the endstate that occurs if the collectivity does not choose a new policy. So, unlike all of the other alternatives from which the collectivity may choose, only $q$ can

48. Each discipline's line of argument identifies situational factors or attributes of those doing the talking (e.g., a reputation for telling the truth) that make persuasion costly or impossible. See Arthur Lupia \& Mathew D. McCubbins, The DemocratiC DiLEMMA 17-64 (1988), for a review of these arguments.

49. We subscript these costs with the letter $i$ to denote the fact that decision costs can vary across individuals. This move allows us to incorporate such costs without committing to a cardinal utility scheme and interpersonal comparability of utility. Avoiding such a commitment is important, as a central tenet of social choice theory is to make positive, rather than normative, judgments about the relative needs of individuals. Of course, these costs can also vary across decision rules, vary across the aspects of the status quo being challenged, or be the object of uncertainty themselves. While incorporating these variations would reinforce the main theme of our argument, we exclude them here to simplify the exposition. 
be achieved without incurring any costs.

Now let there be three legislators, $A, B$, and $C$, who are considering a new policy to replace $q$. The circles in each figure labeled $\mathrm{I}_{A}\left(q \mid K_{A}\right), \mathrm{I}_{B}\left(q \mid K_{B}\right)$, and $\mathrm{I}_{C}\left(q \mid K_{C}\right)$, are a function of $P_{i}\left(K_{i}\right)$ and represent the legislators' preferences with respect to $q$, given each legislator $i$ 's decision costs, $K_{i}$. That is, the area inside a circle represents all of the policies in the space that the legislator named prefers to the status quo (In Figure 1, these circles include all the points in the space that are closer to her ideal point than $q$ ).

In Figure 1, costs are zero for all legislators. The shaded area represents the set of policies that can defeat $q$ in a majority vote. Thus, $x$ will defeat $q$ in a simple, binary, majority vote, while $y$ will not. This figure represents the models cited above well-costs are assumed to be zero and the shaded area is a breeding ground for the instability results described earlier in this section.

\section{FIGURE 1}

WIN SET OF 1 (SHADED) WITH NO COSTS

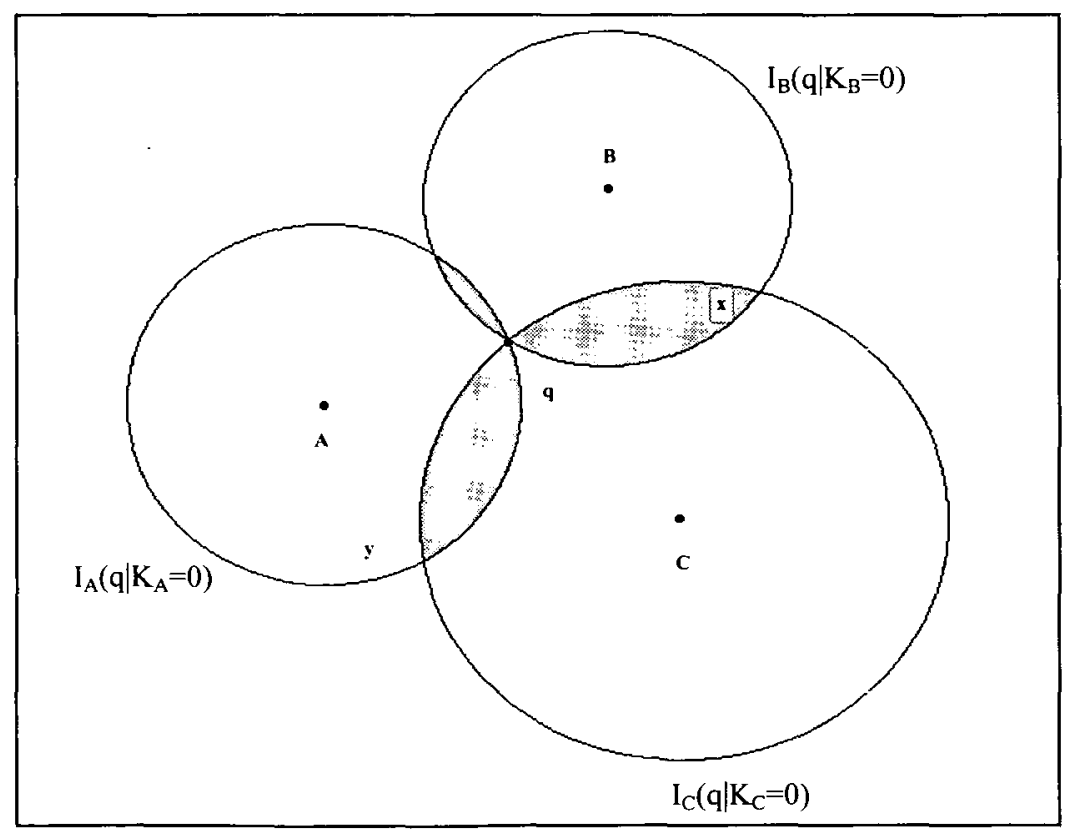


In Figure 2, we add exogenous decision costs. Legislator $A$ faces a cost of $|A-q| / 4$ to change policy, while legislator $B$ faces a cost of $|B-q| / 2$. In comparison to Figure 1 , the shaded area-the set of policies that can beat $q$ in a majority vote shrinks considerably. This set now contains only policy choices acceptable to legislators $A$ and $C$. The kinds of instability identified by Condorcet and McKelvey are more difficult to accomplish in such settings because there are no feasible policy changes that benefit legislator $B$.

FIGURE 2

REDUCTION IN WIN SET WHEN A FACES COST /A-q//4 AND B FACES COST /B-q//2

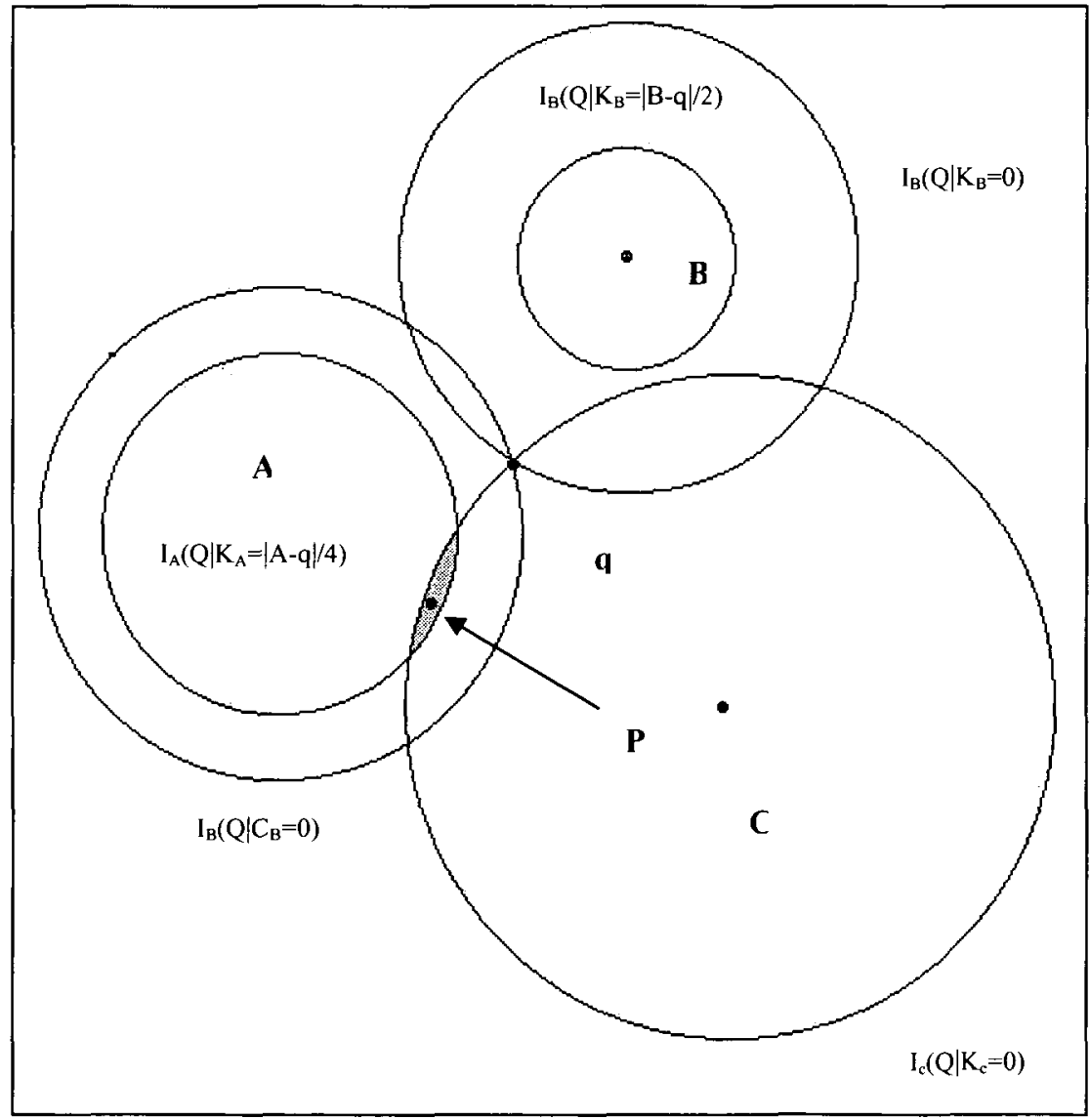


In Figure 3, we increase legislator $A$ 's cost threefold, to $3|A-q| / 4$. This change yields no shaded area, making $q$ stable with respect to individual preferences in this context. Since the costs are exogenous, voters' individual and collective best move is to stick with the status quo. In a world without costs, they might want to choose something different, but - like real legislators-no voter in this model lives in such a costless world. In the context in which they must actually choose, all share a rationale for sticking with the status quo - the costs of changing policy outweigh the benefits for all. There is, therefore, at least a degree of shared intent-all agree that change is not worthwhile.

FIGURE 3

EMPTY WIN SET AS A's COST INCREASES TO 3|A-q $\mid / 4$

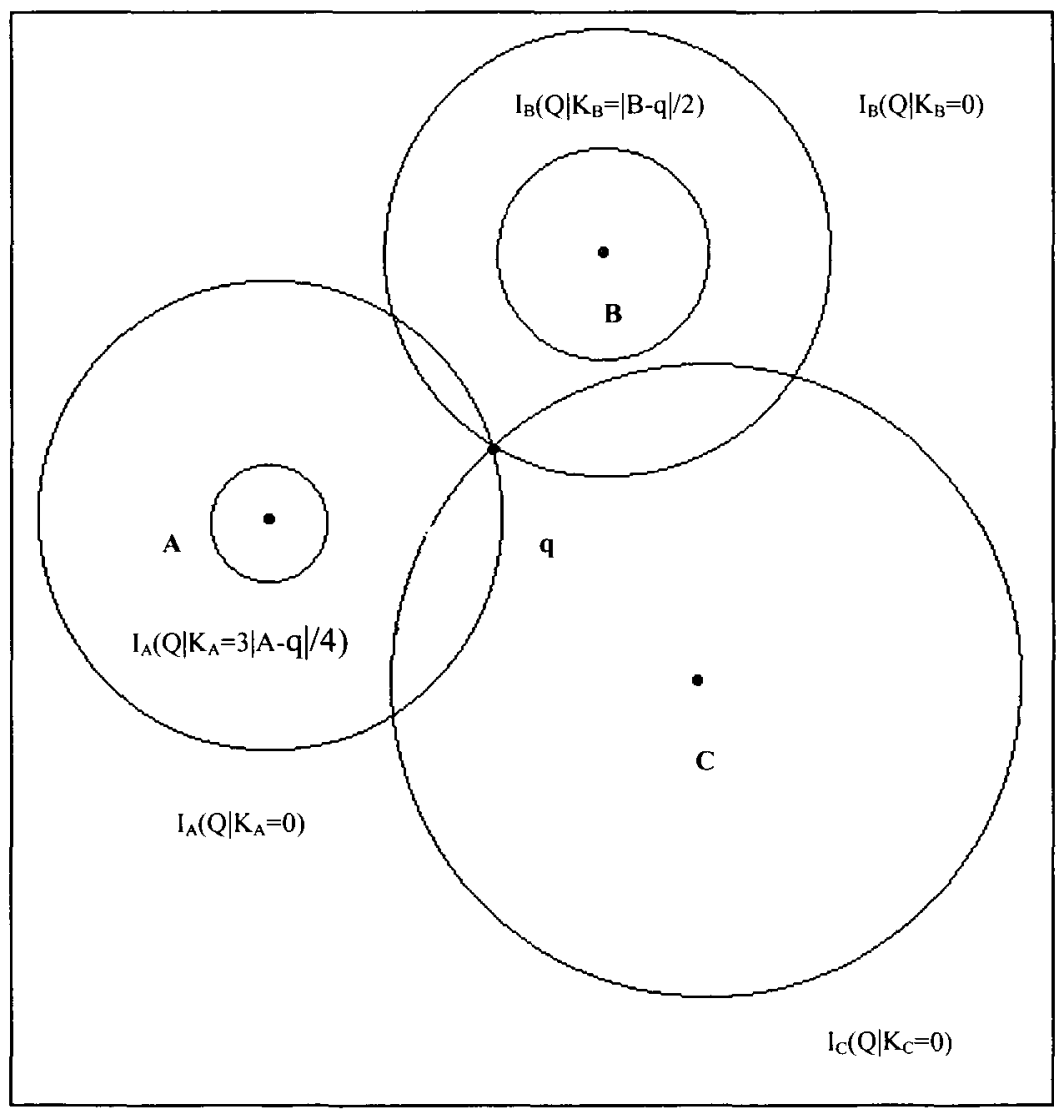




\section{Amendment: Include Exogenous Implementation Costs}

Making a decision and realizing its benefits are not always the same thing. Additional work is often required to get from legislation to implementation. ${ }^{50}$ For example, we may collectively decide to send astronauts to Mars, but it will cost hundreds of billions of dollars and decades of work to implement this decision. We may declare a war on cancer and vow to win it by this decade's end, but our limited knowledge may render victory elusive no matter how much time, money, and attention we invest. Implementation is no trivial matter. ${ }^{51}$ While many factors can make implementation costly, we focus on exogenous factors.

To illustrate how such costs affect stability, consider an example where each alternative in $S$ is represented as a point on a surface in a three dimensional space. The surface is not flat; it is flush with hills and valleys. We then place a group of decision-makers at a point on this surface, and we call this point the status quo, $q$. We assume that the group can move to other locations only "as a group." The group uses MMD to determine whether and where to move.

Let the costs of implementation be determined by the contours of the terrain across which the group moves. In other words, the group must expend energy to climb up and down hills. The higher or steeper the climb, the more costly it is for group members to "implement" a "higher" endstate. The steeper the grade, or the more difficult the climbing surface, the more energy movement requires. Moreover, natural obstacles, such as cliffs, glaciers, or oceans, make moving in certain directions impossible.

If exogenous forces make implementation sufficiently difficult or costly, then it can make unattractive alternatives that would be desirable if implementation were free. Suppose, for example, that if movement were costless, every member of the expedition would prefer to be at a higher altitude. Suppose further that each person is able to contribute only so much energy to the group's climbing effort. Then, the set of moves that are feasible is limited to those that are humanly possible and for which the benefits of moving to a higher altitude outweigh the costs of contributing to the group's climbing effort for a majority of the group.

50. See, e.g., Roger Noll, Reforming Regulation (1971); JefFrey Pressman \& Aaron Wildavsky, Implementation (1973); Paul A. Sabatier \& Daniel B. Mazmanian, Can Regulation Work? (1983); The Politics of Regulation (James Q. Wilson ed., 1980).

51. See, e.g., Thomas R. Palfrey, Implementation in Bayesian Equilibrium: the Multiple Equilibirum Problem in Mechanism Design, in ADVANCES IN ECONOMIC THEORY VOL. 1, at 283 (Jean-Jaques Laffont ed., 1992); JEAN-JAQUES LAFFONT \& JEAN TIROLE, A THEORY OF INCENTIVES IN PROCUREMENT AND REGULATION (1993). 
As was the case in Figures 1-3 above, incorporating implementation costs can restrict the size of the set of proposals that can beat $q$-perhaps even decreasing its size to zero, which would ensure stability.

So even if everyone in the group agrees that it would be great to live in a world where moving to higher endstates is costless, the context in which they actually make decisions - one where exogenous forces make implementation costly - can unify their intent. They may even choose to camp on a hilltop in the shadow of a mountain upon whose top they would all wish to perch if movement were free. Though change is theoretically possible for this group, it chooses stability.

\section{Discussion of a Related Argument}

Our first two amendments involve the addition of exogenously determined costs to the social choice framework. In a sense, they echo Sloss (1973). ${ }^{52}$ She argues that there is "a 'cost of transition' involved in changing from one social state to another" 53 and concludes that " $[t]$ he presence of decision costs in a majority rule voting situation increases the likelihood that a stable outcome will exist." ${ }^{154}$ Our argument differs from Sloss' in at least two ways.

First, Sloss is silent about where costs come from. She notes that "it costs an individual something - in time, effort, or money - to engage in the process of coalition-formation necessary to change the status quo," 55 but this is the extent of her explanation. By contrast, where costs come from is a critical part of our argument (and of Riker's critique). For Riker, stability-inducing costs were the product of institutions; for us, they are the consequence of exogenous forces.

Second, we differ in how costs affect preferences. Sloss treats costs as separable from the value of achieving a different social outcome. As a result, she considers decision costs capable of making player utility functions non-differentiable and individual preferences intransitive. We argue that decision costs should not be separated from the value of achieving a different social outcome when they are a necessary condition for achieving the outcome.

We also contend that a decision-maker's preferences over alternate

52. Judith Sloss, Stable Outcomes in Majority Rule Voting Games, 15 PuBLIC CHOICE 19 (1973).

53. Id. at 21 n. 4 .

54. Id. at 42 .

55. Id. at 21 . 
locations in the space of alternatives need not be independent of his or her current location in that space. This is why our amended social choice theory allows change to be costly and reserves special treatment for the status quo-it can be achieved with no decision costs. In sum, when characterizing individual preferences in social choice theories, we argue that the costs of change should be explicitly integrated into the predecision value of endstates whose realizations require change, particularly when the costs are a consequence of exogenous forces. Clearly, such costs often induce people to prefer stability over change and can unify participants' intent in decision contexts where such costs loom large.

\section{E. Amendment: Include Uncertainty}

In most collective choice contexts, individuals lack information about the consequences of their actions. In some cases, limited information induces stability by reducing the number of alternatives to the status quo of which people are aware. In other cases, information effects are more subtle. If people are risk averse, then limited information can make them apprehensive about trying new things ${ }^{56}$ and effectively limit the number of alternatives that an individual or group is willing to consider. Such effects can bind people to certain outcomes and induce stability in places where it would not exist if everyone were omniscient.

Returning to the mountainous expedition described earlier, limited information is analogous to limited vision - each individual's perceptive capacity interacts with the topography of the location to limit the number of alternative locations she can see. A person standing at the foot of a mountain may be unable to see beyond it to possibly higher distant peaks. Her limited vision may make her uncertain about the work needed to reach a higher endstate and, if movement is costly, may dissuade her from moving. Clouds, fog, and the horizon may have similar effectsthey prevent people from seeing higher mountaintops, even if loftier peaks are close by and easy to reach in reality. ${ }^{57}$

To put this idea into the lexicon of social choice theory, let the matrix $I$ be the "information profile." An information profile specifies what each individual knows about the post-implementation (endstate) value of each policy alternative. Each row of the matrix corresponds to an individual; each column corresponds to an alternative. Therefore each element of the profile represents what a particular person knows about a

56. See, e.g. Daniel Kahneman \& Amos Tversky, Choices, Values, and Frames, 39 AMERICAN PSYCHOLOGIST 341 (1984).

57. And even if everyone in the group can see a higher mountaintop and would rather be there if movement were free and easy, their limited vision can be the basis of an implementation cost if it prevents them from seeing "how to get to there from here." 
particular alternative. We assume that the perceived value of an endstate is a function of information. Let $P(I)$ be the profile of individual preferences over alternatives in $S$ given information $I$.

To see the impact of uncertainty, consider Table 1. It presents two preference profiles, one is the complete information profile $I^{c}$ and the other is the incomplete information profile $I^{i}$. Let $x$ be the sole subject of uncertainty in information profile $I^{i}$ and suppose that voters are so averse to uncertainty that $x$ drops to the bottom of their respective preference orderings. Given MMD as the CCR, the uncertainty is sufficient to induce stability in the example. The complete information case yields Condorcet's paradox. The incomplete information case, by contrast, yields stability: no alternative can defeat $y$ (as legislators 1 and 2 now prefer $y$ to $z$ and $x$ ).

\section{TABLE 1}

INCOMPLETE INFORMATION AND RISK AVERSION TOGETHER INDUCE STABILITY

\begin{tabular}{|c|c|c|c|c|c|c|}
\hline & $P(P)$ & & & & $P(T)$ & \\
\hline 1 & 2 & 3 & & 1 & 2 & 3 \\
\hline $\mathrm{x}$ & $\mathrm{y}$ & $\mathrm{z}$ & & $\mathrm{y}$ & $\mathrm{y}$ & $\mathrm{z}$ \\
\hline $\mathrm{y}$ & $\mathrm{z}$ & $\mathrm{x}$ & & $\mathrm{z}$ & $\mathrm{z}$ & $\mathrm{y}$ \\
\hline $\mathrm{z}$ & $\mathrm{x}$ & $\mathrm{y}$ & & $\mathrm{x}$ & $\mathrm{x}$ & $\mathrm{x}$ \\
\hline
\end{tabular}

Individual information shortcomings can affect group decisions in other ways. As suggested by research in psychology, ${ }^{58}$ economics, ${ }^{59}$ and political science, ${ }^{60}$ information asymmetries limit what people are willing to say to each other and what listeners are willing to believe. For example, when a speaker fears that a particular utterance will offend her

58. See, e.g., Richard E. PETTY \& JoHn T. CACIOPPo, COMMUNICATION AND Persuasion: Central and Peripheral Routes to Attitude Change (1986); Alice H. EAGly \& SHELly Chaiken, The Psychology of AtTitudes (1993).

59. See, e.g., Michael Spence, Job Market Signaling, 87 THE QuARTERLY Journal of ECONOMICS 355 (1973); Vincent P. Crawford \& Joel Sobel, Strategic Information Transmission, 50 ECONOMETRICA 1431 (1982); Joseph Farrell \& Robert Gibbons, Straight Talk with Two Audiences, 79 AM. ECON. REV. 1214 (1989).

60. See, e.g., Jeffrey S. Banks, Signaling Games in Political Science (1991); arthur Lupia \& Mathew D. Mccubbins, The Democratic Dilemma (1988). 
audience or turn them against her she may fail to provide information that would actually help them. In such cases, information asymmetries limit the number of alternatives that members of collectivities can convince each other to consider. Put another way, and returning to the mountains for one final example, one person with exceptional vision may be able to see mountaintops that no one else can see. If that person lacks the ability to persuade the others of the mountaintop's existence, then movement to those mountaintops will not occur. An appendix contains an additional, though more involved, example, that shows how exogenous costs and information effects combine to limit the instability in the McKelvey model. ${ }^{61}$

\section{F. Main Implication}

Our amendments clarify how exogenous forces affect the social choice instability results. They make policy change costly and the consequences of such changes uncertain. When considered together they are powerful and often induce stability.

That such forces are strong and ever present in our lives explains why when we examine the collective choices that do or can affect our lives, instability never seems to be the problem ${ }^{62}$ - the problem is actually getting something done. ${ }^{63}$ Limited cognitive ability, the difficulty of persuasion, decision costs and other exogenous factors each reinforce what we call Newton's First Law of Social Choice: It is easier for groups to stay where they are than it is for them to move. These forces induce group members to share the intention of leaving things as they are.

This way of thinking leads us to disagree with Riker's claim that "in the long run, nearly anything can happen in politics." ${ }^{\text {"64 }}$ Riker's conclusion ignores the fact that tendencies in what humans can perceive, systematic limits on persuasion, and propensity to fear the unknown generates preferences for certain types of outcomes-particularly the status quo. While nearly anything can happen in social choice theory's models of politics, it is wrong to draw the same conclusion about existing legislative domains. There, 'disequilibrium' is not the characteristic feature of politics.

61. Richard D. McKelvey, Intransitivities in Multidimensional Voting Models and Some Implications for Agenda Control, 12 J. ECON. THEORY 472 (1976).

62. See Gordon Tullock, Why So Much Stability, 37 Public ChOICE 189 (1981).

63. E.g., Mancur Olsen JR., The Logic of Collective Action: Public Goods AND THE THEORY OF GROUPS (1965).

64. William H. Riker, Implications from the Disequilibrium of Majority Rule for the Study of Institutions, 74 AM. POL. SCI. REV. 432, 446 (1980). 


\section{CONCLUSION}

Neither Arrow's General Possibility Theorem nor the focal instability results of social choice theory is sufficient to prove that legislative intent is meaningless or does not exist. To claim that it does is to misunderstand or misinterpret the results.

The results do, however, provide warnings about blithely accepting general normative claims about collective choices. Arrow's Theorem precludes a select set of universal claims about what qualities a method of collective choice can have. The instability results identify certain theoretical conditions under which instability will be rampant. Such points are beyond disagreement. But there is an important difference between demonstrating that some claims about collective intent are logically incoherent - which the social choice results do-and demonstrating that all such claims are meaningless. For this latter task, the social choice results are insufficient or - as Thomas Schwartz once concluded about the instability results: "[w]hat you have seen so far is not that collective choices are always unstable, or even that they are ever unstable, but only that they can be unstable." 65

Having demonstrated that Arrow's Theorem and the instability results do not negate legislative intent, what can we say about statutory interpretation more generally? We hope that readers come away from this article with the understanding that the answer to this question requires insights that social choice theory is ill equipped to offer. Because cooperative game theory does not allow us to draw precise conclusions about how and why individuals adapt to the exogenous forces and actions of others that characterize real choice contexts, it provides a weak foundation for answering questions about intentionality-individual or collective.

Non-cooperative game theory offers a better logical foundation. It allows analysts to draw clearer causal connections between what people want and what they do when they are able to adapt strategically to adverse conditions in their environment. Scholars, such as Shepsle ${ }^{66}$ and McCubbins and Rodriguez, ${ }^{67}$ have begun to incorporate such insights

65. Thomas Schwartz, Votes, Strategies, and Institutions: An Introduction to the Theory of Collective Choice, in CONGRESS: StRuCTURE AND POLICY 329 (Mathew D. McCubbins \& Terry Sullivan eds., 1987).

66. Kenneth A. Shepsle, Congress Is a "They" Not an "It": Legislative Intent as Oxymoron, 12 INT'L REV. LAW \& ECON. 239 (1992).

67. Mathew D. McCubbins \& Daniel B. Rodriguez, Theories of Law and Statutory Interpretation, What STATUTES MEAN (Mathew D. McCubbins \& Daniel B. Rodriguez 
into their contributions to the legislative intent debate.

In addition to logic, questions about intent should also have an empirical reference-after all, intentionality refers to a mental state. Clarifying the conditions under which scholars can draw reliable inferences about individual or collective intent requires knowledge of not only the relationship between individual thought and action but also about how these factors correspond to common thoughts and intentions that a group can share. Since it is possible for individuals to share beliefs and preferences in common, the idea that an analyst can draw a reliable inference about collective intent is less easily dismissed than many critics allege.

Our continuing work in this area ${ }^{68}$ builds from an integrated foundation of non-cooperative game theory and relevant research lines in psychology. In it, we are identifying conditions under which reliable inferences about legislative intent and the meaning of statutes can be drawn.

eds., 2004).

68. Arthur Lupia \& Mathew D. McCubbins, When Can Legislative Records Aid Statutory Interpretation? Inference, Credibility, and Collective Intent in the United States Congress, in What Statutes Mean (Mathew D. McCubbins \& Daniel B. Rodriguez eds., 2004). 


\section{APPENDIX \\ COSTS, UNCERTAINTY, AND MCKELVEY'S \\ GLOBAL CYCLING THEOREM}

In a classic 1976 article, McKelvey proved that:

[I]n the case where all voters evaluate policy in terms of a Euclidean metric, if there is no equilibrium outcome, then the intransitivities extend to the whole policy space in such a way that all points are in the same cycle set. The theoretical implication of this result is that it is theoretically possible to design voting procedures which, starting from any given point, will end up at any other point in the space of alternatives, even at Pareto dominated ones. ${ }^{69}$

McKelvey derived his result from a standard spatial model. As noted in the text, a characteristic of such models is that they portray collective choice as occuring in the absence of decision costs, implementation costs, and uncertainty.

What happens to McKelvey's main result-that MMD can lead to a majority supporting any point in the choice space regardless of how large the distance between that point and their ideal points-if we incorporate these factors into the standard model? A simple, but suggestive example answers the question.

Our example is based on McKelvey's model, with two notable differences. The first difference concerns the number of voters and policy dimensions. McKelvey proves his theorem for $n$ voters and $m$ policy dimensions, where both $n$ and $m$ are finite. Our demonstration involves 3 voters, 2 policy dimensions, and 1 cost-related dimension. Our simplification entails no loss of generality (i.e., it is easy to replicate in higher dimensional spaces). The second difference is that we introduce implementation costs and voter uncertainty.

There are three voters $V=\left\{v_{1}, v_{2}, v_{3}\right\}$. The voters use majority rule to choose points on $S$, a three-dimensional Euclidean surface, $S=\Re^{3}$. We call the first dimension $x \in \mathscr{R}$, the second dimension $y \in \mathscr{R}$, and the third dimension $c \in \mathscr{R}$. We call alternatives in $S s_{q}, s_{l}, s_{2}, \ldots s_{n}$, where the subscript $q$ denotes the status quo and the other subscripts denote the order in which the alternatives are voted on. So, if there is a first vote, then it is between $s_{q}$ and $s_{l}$; if there is a second vote, then it is between $s_{2}$

69. Richard D. McKelvey, Intransitivities in Multidimensional Voting Models and Some Implications for Agenda Control, 12 J. ECON. THEORY 472, 472 (1976). 
and the winner of the first vote, and so on. Let $n \in\{1, \ldots, N\}$, where $N$ is finite, denote the number of the vote. For $n>1$, let $w_{n} \in S$ denote the winner of the $n^{t h}$ vote and let $w_{n-l} \in S$ denote the winner of the $n-I^{\text {th }}$ vote. For $n=1$, let $w_{n-1}=s_{q}$.

Like McKelvey, we assume that each voter has a policy utility function $U i: S \rightarrow \Re$, that is a monotone decreasing function of Euclidean distance; i.e., for all $v_{i} \in V$, and $n \in\{0 \ldots N\}, \exists w_{n} \in S$ such that $U_{i}\left(w_{n}\right)=-/ / w_{n}-v_{i} / /$, where $\|\cdot\|$ represents the standard Euclidean norm. Note that, in a moment, we will offer a more comprehensive utility function that factors in implementation costs and uncertainty.

Let $c \in R$, which is the name of the third dimension in $S$, represent implementation costs. Here, the implementation cost is a function of the change on the $x$-dimension that occurs as a consequence of the election result. For $n>1$, let $x_{n}$ denote the location on the $x$-axis of the winner of the $n^{\text {th }}$ vote and let $x_{n-1}$ denote the location on the $x$-axis of the winner of the $n-l^{\text {th }}$ vote. For $n=1$, let $x_{n-1}$ be the location of $s_{q}$ on the $x$-axis. Then, for any election $n, c=\left|x_{n}-x_{n-1}\right|$.

Put another way, $S$ is the standard two-dimensional Euclidean plane folded along the $y$-axis with movements away from $x=0$, in either the positive or negative direction, implying an increase in horizontal and vertical distance from $x=0$. This representation of the policy space implies that climbing up or down the $x$-axis is equally costly and that the only moves that are free to implement are moves along lines that are parallel to the $y$-axis.

Now we add uncertainty. There are many ways in which this can be done. We choose a simple one. Let $Z \in\left\{1, Z^{h}\right\}$ represent the unknown factors associated with the cost of implementation, let $Z^{h}>1$ be a multiplier relevant to a scenario where the implementation costs are higher than $c$, and let $z \in[0,1]$ be the common prior probability that $Z=Z^{h}>1$. In other words, we assume that all individuals believe that there is a chance $(z)$ that implementing a new policy will cause unexpected problems $Z^{h}$.

Then $U_{i}\left(w_{n}, c, z, Z^{h}\right)$ is voter i's total utility function, whose component parts are his or her policy utility, the implementation costs required to move from one point in $S$ to another, and his or her uncertainty. In other words, for each voter at each vote $n$, there is a total utility function $C C U_{i}: S \rightarrow \Re$, which for all $v_{i} \in V, \exists\left\{w_{n-1}, w_{n}\right\} \in S \times S$ such that the expected utility from changing the status quo is $-\left\|s_{n}-v_{i}\right\|-[(1-z) c]-\left[z Z^{h} c\right]$ and the utility from retaining the status quo is $=-\| / w_{n-I}-v_{i} \mid /$.

Like McKelvey, we follow the cooperative game theoretic norm of assuming that voters vote sincerely. Here, this assumption implies that every time voters are asked to vote, they select from the set of alternatives 
offered to them $\left\{s_{n}, w_{n-1}\right\}$ the element that corresponds to their highest total utility. An implication of this assumption is that voters are myopic, in that they do not look beyond the consequences of the current vote when deciding what do to. We contend that allowing voters to think about future implications of their current actions could also induce stability, but we preserve this assumption in the example to make the effect of costs and uncertainty on the McKelvey model simple and clear.

Using policy utility functions, McKelvey shows that "it is theoretically possible to design voting procedures which, starting from any given point, will end up at any other point in the space of alternatives, even at Pareto dominated ones." ${ }^{.70}$ Our example shows why the same need not be true for total utility functions.

Let $s_{q}=(0,0), v_{1}=(-2,0), v_{2}=(0,2)$, and $v_{3}=(2,0)$. Then the policy utility and the total utility from $s_{q}$ for each voter are -2 . Suppose further that $\mathrm{S}=\left\{s_{1}=(-1.9,-1.9), s_{2}=(0.5,3.8), s_{3}=(0.6,-3.7)\right\}$ and that, for the moment, $z=0$. Considering policy utility only, Table A-1 reveals the McKelvey result - the group attains a Pareto dominated outcome $\left(s_{q}\right.$ Pareto dominates $s_{3}$ ) in just three votes. Asterisks in Table 1 denote the individuals for whom $s_{n}$ provides higher policy utility than $s_{n-I}$.

TABLE A-1

\begin{tabular}{|c|c|c|c|c|}
\hline & $\begin{array}{c}\text { Policy Utility } \\
\text { from } \mathrm{s}_{q}\end{array}$ & $\begin{array}{c}\text { Policy Utility } \\
\text { from } \mathrm{s}_{1}\end{array}$ & $\begin{array}{c}\text { Policy Utility } \\
\text { from } \mathrm{s}_{2}\end{array}$ & $\begin{array}{c}\text { Policy Utility } \\
\text { from } \mathrm{s}_{3}\end{array}$ \\
\hline $\mathrm{V}_{1}$ & -2 & $-1.9^{*}$ & -4.55 & $-4.52^{*}$ \\
\hline $\mathrm{V}_{2}$ & -2 & $-1.9^{*}$ & $-1.87^{*}$ & -5.73 \\
\hline $\mathrm{V}_{3}$ & -2 & -4.34 & $-4.08^{*}$ & $-3.92^{*}$ \\
\hline
\end{tabular}

Table A-2 displays the same situation inclusive of implementation costs. Asterisks in Table 2 denote the individuals for whom $w_{n}$ provides higher total utility than $w_{n-1}$-but there are no asterisks. The implementation costs in this example are sufficient to protect the status quo policy from many challenges. In fact, an implementation cost of just greater than.$l$ is sufficient to prevent any element of $S$ from defeating $s_{q}$ in this example.

70. Richard D. McKelvey, Intransitivities in Multidimensional Voting Models and Some Implications for Agenda Control, 12 J. ECON. THEORY 472, 472 (1976). 
TABLE A-2

\begin{tabular}{|c|c|c|c|c|}
\hline & $\begin{array}{c}\text { CC Utility } \\
\text { from } \mathrm{s}_{q} \text { at } n=1\end{array}$ & $\begin{array}{c}\text { CC Utility } \\
\text { from } \mathrm{s}_{1} \text { at } n=1\end{array}$ & $\begin{array}{c}\text { CC Utility } \\
\text { from } \mathrm{s}_{2} \text { at } n=2\end{array}$ & $\begin{array}{c}\text { CC Utility } \\
\text { from } \mathrm{s}_{3} \text { at } n=3\end{array}$ \\
\hline $\mathrm{V}_{1}$ & -2 & -3.8 & -5.05 & -4.82 \\
\hline $\mathrm{V}_{2}$ & -2 & -3.8 & -2.37 & -6.33 \\
\hline $\mathrm{V}_{3}$ & -2 & -6.24 & -4.58 & -4.52 \\
\hline
\end{tabular}

In our example so far, $S$ has only three elements. What happens if we allow, just as McKelvey does, an exogenous agenda setter to choose, as $s_{n}$, any point on the $x y$ surface? Applying the Pythagorean theorem shows that the lowest amount of policy utility that the player with the highest policy utility could earn as the result of a majority decision to move from $s_{q}$ to any other point on the $x y$ surface is $-\sqrt{2}$. Therefore, any implementation cost of greater than $2-\sqrt{2}$ is sufficient to prevent any point on the $x y$-surface from defeating $s_{q}$ in a majority vote. This cost is not very high relative to the payoffs in Table A-2.

If we add uncertainty to the example, then the minimum implementation cost sufficient to induce stability falls even more. Suppose that $Z=I$ in reality (i.e., the "bad implementation scenario", $Z^{h}$, will not be realized). The only difference between this and the previous paragraph is voter uncertainty - the objective situation is no different. With this uncertainty the lowest implementation cost sufficient to induce stability shrinks from $2-\sqrt{2}$ to just above 0 . To see why, note that the possible range of prior beliefs that support the reality $Z=1$ is $z \in[0,1)$. In other words, the voters are concerned about the "bad implementation scenario," though after the election they will learn that their fears were unfounded. In this case, the minimum implementation cost required to protect $s_{q}$ is now:

$$
\frac{2-\sqrt{2}}{((1-z) c)+z c Z^{h}}
$$

So as $z$ or $Z^{h}$ increases, the minimum implementation cost required to protect $s_{q}$ from all challenges falls. And as long as $c>0$, there exist values of $z$ and $Z^{h}$ sufficient to induce stability. Put another way, as $c$ or $Z^{h}$ increases, the minimum amount of uncertainty that is sufficient to induce stability decreases. Stated differently, even the smallest amount of uncertainty can induce stability.

We are not, however, arguing that McKelvey's claim is untrue. His argument is logically coherent. We are, however, arguing against other 
scholars' claims that McKelvey's result is directly relevant to debates about legislative intent. To believe such conclusions applicable to debates about legislative intent, one must also believe that the assumptions on which McKelvey's result is based (i.e., policy change entails no uncertainty or implementation costs) are true for actual legislative contexts or that the assumptions are false, but his result holds nevertheless. The former is ridiculous and the latter we have just shown to be false. 